\title{
Dental tissue proportions in fossil orangutans from mainland Asia and Indonesia
}

\author{
Tanya M. Smith,1,2 Anne-Marie Bacon,3 Fabrice Demeter, 4 Ottmar Kullmer,5 \\ Kim Thuy Nguyen, 6 John de Vos, 7 Wang Wei, 8 John P. Zermeno, ${ }^{1}$ Lingxia Zhao9 \\ 1 Department of Human Evolutionary Biology, Cambridge, MA, USA; 2Department of Human \\ Evolution, Max Planck Institute for Evolutionary Anthropology, Leipzig, Germany; ${ }^{3}$ CNRS UPR \\ 2147, Dynamique de I'Evolution Humaine: Individus, Populations, Espèces, Paris, France; \\ 4 Muséum National d'Histoire Naturelle, Dépt. Homme, Nature, Sociétés, UMR 7206/USM104 \\ Ecoanthropologie et Ethnobiologie, Paris, France; 5 Department of Paleoanthropology and Messel \\ Research, Senckenberg Research Institute, Frankfurt am Main, Germany; 6 Institute of \\ Archaeology, Vietnam Academy of Social Sciences, Ha noi, Vietnam; ${ }^{7}$ Department of Geology, \\ Netherlands Center for Biodiversity Naturalis, Leiden, The Netherlands; ${ }^{8}$ Natural History Museum \\ of Guangxi Zhuang Autonomous Region, Nanning, China; 9 Institute of Vertebrate Paleontology \\ and Palaeoanthropology, Chinese Academy of Sciences, Beijing, China
}

\begin{abstract}
Orangutans (Pongo) are the only great ape genus with a substantial Pleistocene and Holocene fossil record, demonstrating a much larger geographic range than extant populations. In addition to having an extensive fossil record, Pongo shows several convergent morphological similarities with Homo, including a trend of dental reduction during the past million years. While studies have documented variation in
\end{abstract}

Correspondence: Dr. Tanya M. Smith, Department of Human Evolutionary Biology, Harvard University, 11 Divinity Avenue, Cambridge, MA 02138, USA. E-mail: tsmith@fas.harvard.edu

Key words: enamel thickness, primate evolution, Pongo, dental morphology, human evolution.

Acknowledgements: the authors acknowledge Jean-Jacques Hublin, Anthony Olejniczak, Charis $\mathrm{Ng}$, Stefan Reh, and Heiko Temming for assistance with micro-CT scanning, figure preparation, virtual analyses and/or comments on the manuscript; Russ Ciochon, Rick Potts, and Reinier van Zelst for their assistance with fossil access. They also thank the following museums and research institutes: Naturalis (Leiden), Senckenberg Institute (Frankfurt), Institute for Vertebrate Paleontology and Paleoanthropology (Beijing), and the Institute of Archaeology in Ha noi. This study has been funded by the Max Planck Society, Harvard University, and the Harvard Medical School Milton Fund.

Received for publication: 30 July 2011.

Revision received: 18 0ctober 2011.

Accepted for publication: 18 October 2011.

(C) Copyright T.M. Smith et al., 2011

Licensee PAGEPress, Italy

Human Origins Research 2011; 1:e1

doi:10.4081hor.2011.e1

This work is licensed under a Creative Commons Attribution NonCommercial 3.0 License (CC BY-NC 3.0). dental tissue proportions among species of Homo, little is known about variation in enamel thickness within fossil orangutans. Here we assess dental tissue proportions, including conventional enamel thickness indices, in a large sample of fossil orangutan postcanine teeth from mainland Asia and Indonesia. We find few differences between regions, except for significantly lower average enamel thickness (AET) values in Indonesian mandibular first molars. Differences between fossil and extant orangutans are more marked, with fossil Pongo showing higher AET in most postcanine teeth. These differences are significant for maxillary and mandibular first molars. Fossil orangutans show higher AET than extant Pongo due to greater enamel cap areas, which exceed increases in enamel-dentine junction length (due to geometric scaling of areas and lengths for the AET index calculation). We also find greater dentine areas in fossil orangutans, but relative enamel thickness indices do not differ between fossil and extant taxa. When changes in dental tissue proportions between fossil and extant orangutans are compared with fossil and recent Homo sapiens, Pongo appears to show isometric reduction in enamel and dentine, while crown reduction in $H$. sapiens appears to be due to preferential loss of dentine. Disparate selective pressures or developmental constraints may underlie these patterns. Finally, the finding of moderately thick molar enamel in fossil orangutans may represent an additional convergent dental similarity with Homo erectus, complicating attempts to distinguish these taxa in mixed Asian faunas.

\section{Introduction}

The fossil record of the genus Pongo has been traced into the Pleistocene and/or Holocene of Java, Borneo, Sumatra, China, Laos, Thailand, Cambodia, and Vietnam. - $6^{-6}$ The vast majority of evidence comes from over 5000 isolated teeth, as well as fragmentary craniodental material 5,7 and two partial skeletons. ${ }^{8,9}$ Several species and subspecies have been named, largely on the basis of dental metric variation, occlusal morphology, and geographic location, $1,3,5$ although these will not be considered here as species-level taxonomy is not the focus of this paper. In contrast, almost nothing is known about the fossil record of Gorilla or Pan, save for three chimpanzee teeth recovered 
from Kenyan Middle Pleistocene deposits. ${ }^{10}$ Fossil orangutan dentitions are larger than extant populations, $1,5,11,12$ as is true of most fossil members of the genus Homo.13

The issue of size reduction in Pleistocene and Holocene Asian faunas has received considerable paleoanthropological attention, particularly following discovery of the remarkably small hominins from Flores. ${ }^{14}$ Harrison and colleagues 15 suggest that mainland Asian and Sumatran fossil orangutan dental material is $\sim 20 \%$ and $\sim 15 \%$ larger than extant orangutans, respectively. Smith and Pilbeam 16 hypothesized that if fossil orangutans were megadont (having larger teeth than predicted by body mass), this condition may represent a dietary adaptation or evidence for rapid phyletic dwarfing. Initial analysis of the only adult skeleton recovered to date suggested that mainland fossil orangutans were markedly megadont, ${ }^{8}$ although revised postcranial estimates of the skeleton are comparable to that of extant male orangutans, ${ }^{9}$ implying a more minor degree of megadonty.

Molecular analyses of extant orangutans suggest that Bornean (Pongo pygmaeus) and Sumatran (Pongo abelli) populations diverged between 0.4-3.6 million years ago. ${ }^{17-21}$ de $\operatorname{Vos}^{22,23}$ has argued that the Indonesian paleoenvironmental record reveals a more recent divergence, while Harrison et al. ${ }^{15}$ hypothesized that orangutans dispersed into Sundaland during a cold phase in the late Pliocene ( 2.7 mya) and fragmented at the start of the Pleistocene ( 1.8 mya), becoming genetically distinct subsequent to this. Unfortunately little is known about the biogeography of Early Pleistocene orangutans, due in part to the limited fossil record, lack of securely dated sites, and ambiguity regarding the taxonomic identification of primate material.4,12,15,23,24

Analyses of tooth morphology and cranial measurements suggest that variation within extant Bornean orangutans is greater than or equal to the variation between Bornean and Sumatran orangutans. ${ }^{25-27}$ Comparisons of dental enamel thickness between the two species also reveal highly overlapping ranges and statistically indistinguishable means. ${ }^{28,29}$ This is somewhat surprising given differences in jaw morphology and the material properties of dietary items between the two species. 30,31 Gantt ${ }^{32}$ and Ho et al. ${ }^{4}$ noted that fossil orangutans show thick enamel, although this was not quantified in either study, nor were comparisons made among fossil groups. Ho et al. ${ }^{4}$ suggested that thicker enamel in fossil orangutans relative to extant orangutans may have been part of a suite of characteristics that facilitated more diverse locomotor behavior as well as dietary ecology. Large tooth size, coupled with thick enamel, has been hypothesized to resist abrasion or tooth fracture during mastication (reviewed in $33-35$ ).

This study quantifies and compares dental tissue proportions, including conventional two-dimensional (2D) enamel thickness indices, in Asian mainland and island fossil orangutan communities. Given patterns of size variation between regions and the temporal trend in dental reduction, it is unclear if enamel thickness varied between geographic regions, nor how fossil orangutans compare to extant orangutans. A better understanding of enamel thickness may also help to sort fossil orangutans from hominins in mixed Asian Pleistocene primate faunas, which are particularly difficult to distinguish from external morphology alone. $., 24,36,37$ Finally, these results are considered in light of recent studies of enamel thickness within fossil and extant Homo sapiens, $35,38-40$ which are known to show a similar pattern of dental reduction over the same period. Given the significance of enamel thickness in assessments of hominoid systematics $28,29,32,35,41$ and dental functional morphology, $33,34,42,43$ characterization of enamel thickness within a geographically and temporally diverse hominoid genus will also permit more refined comparisons of limited samples of other fossil apes and humans.

\section{Materials and Methods}

The fossil sample consists of 153 postcanine teeth (Table 1) imaged with micro-CT scanning according to established techniques (Supplementary Information). Virtual 2D section planes were generated from three-dimensional models with VG Studio MAX 2.0 software (Volume Graphics, Inc.) according to published protocols. ${ }^{29,35,41,45}$ Several variables were quantified on 2D section planes following Martin:41,45 enamel cap area (c), enamel-dentine junction length (e), and coronal dentine area enclosed by the enamel cap (b) (Figure 1). Average enamel thickness (AET) is calculated as [c/e], yielding the average straight-line distance (mm units), or thickness, from the enamel-dentine junction to the outer enamel surface. Given that fossil orangutan dentitions vary in size between regions and when compared with extant taxa, AET was scaled for comparisons by calculation of relative enamel thickness (RET): [100* [c/e ]/ sq. rt. b].

Previous studies have demonstrated significant differences in hominoid enamel thickness among tooth positions and between maxillary and mandibular rows, ${ }^{28,38,40}$ thus tooth positions were assessed separately. The Mann-Whitney $U$ test was performed with IBM SPSS Statistics software (v.18), where sample sizes were four or greater to compare enamel thickness indices and their components between mainland Asian and Indonesian fossil orangutans. It was not possible to assess temporal variation due to the uncertainty of dates for the Chinese apothecary and Sumatran cave material (see Supplementary Information), which constitute the majority of the fossil sample. Variables were also compared between pooled fossil samples and a comparative extant sample of 193 Bornean and Sumatran postcanine teeth ${ }^{28,29}$ using the Mann-Whitney $U$ test.

Table 1. Fossil orangutan sample employed for enamel thickness assessment.

\begin{tabular}{|c|c|c|c|c|c|c|c|c|c|}
\hline Country & Sites/Collection & Row & P3 & P4 & M1 & M2 & M3 & M? & Total \\
\hline Sumatra & Lida Ajer, Sibrambang, Djamboe Caves & $\begin{array}{l}\text { Max } \\
\text { Mand }\end{array}$ & $\begin{array}{l}0 \\
0\end{array}$ & $\begin{array}{l}0 \\
0\end{array}$ & $\begin{array}{l}17 \\
12\end{array}$ & $\begin{array}{l}17 \\
13\end{array}$ & $\begin{array}{l}12 \\
14\end{array}$ & $\begin{array}{l}2 \\
1\end{array}$ & $\begin{array}{l}48 \\
40\end{array}$ \\
\hline Borneo & Niah Cave & $\begin{array}{l}\text { Max } \\
\text { Mand }\end{array}$ & $\begin{array}{l}0 \\
0\end{array}$ & $\begin{array}{l}0 \\
0\end{array}$ & $\begin{array}{l}0 \\
2\end{array}$ & $\begin{array}{l}0 \\
0\end{array}$ & $\begin{array}{l}0 \\
0\end{array}$ & $\begin{array}{l}1 \\
0\end{array}$ & $\begin{array}{l}1 \\
2\end{array}$ \\
\hline Vietnam & Duoi U'Oi & $\begin{array}{l}\text { Max } \\
\text { Mand }\end{array}$ & $\begin{array}{l}1 \\
3\end{array}$ & $\begin{array}{l}1 \\
4\end{array}$ & $\begin{array}{l}0 \\
1\end{array}$ & $\begin{array}{l}2 \\
0\end{array}$ & $\begin{array}{l}0 \\
1\end{array}$ & $\begin{array}{l}0 \\
1\end{array}$ & $\begin{array}{c}4 \\
10\end{array}$ \\
\hline China & Chinese Apothecary (Senckenberg, IVPP) & $\begin{array}{l}\text { Max } \\
\text { Mand }\end{array}$ & $\begin{array}{l}0 \\
0\end{array}$ & $\begin{array}{l}0 \\
0\end{array}$ & $\begin{array}{l}14 \\
11\end{array}$ & $\begin{array}{l}2 \\
3\end{array}$ & $\begin{array}{l}3 \\
1\end{array}$ & $\begin{array}{l}4 \\
0\end{array}$ & $\begin{array}{l}23 \\
15\end{array}$ \\
\hline & Ganqian Cave, Guangxi & $\begin{array}{l}\text { Max } \\
\text { Mand }\end{array}$ & $\begin{array}{l}1 \\
1\end{array}$ & $\begin{array}{l}2 \\
1\end{array}$ & $\begin{array}{l}0 \\
0\end{array}$ & $\begin{array}{l}0 \\
0\end{array}$ & $\begin{array}{l}1 \\
0\end{array}$ & $\begin{array}{l}2 \\
2\end{array}$ & $\begin{array}{l}6 \\
4\end{array}$ \\
\hline & Total & & 6 & 8 & 57 & 37 & 32 & 13 & 153 \\
\hline
\end{tabular}

Max, maxillary element; mand, mandibular element; P, premolar; M, molar; M?, uncertain molar position. 


\section{Results}

No significant differences are found between Asian and Indonesian fossil orangutan maxillary molars, but Indonesian mandibular first molars (M1s) show significantly thinner average enamel thickness (AET) values (Figure 2, Table 2). This appears to be due, in part, to differences in tooth size; Indonesian fossil orangutans show significantly lower enamel cap areas (c) and dentine areas (b) than mainland Asian orangutans. Enamel-dentine junction lengths (e) and relative enamel thickness (RET) values were also lower in mandibular M1s from Indonesian fossil orangutans, but these differences were not significant. Due to limited samples for sites outside of Sumatra, it was not possible to compare fossil samples within mainland Asia or Indonesia, although visual inspection of the data showed broadly similar values within regions.

Despite the sole difference in mandibular M1s between regions, fossil samples were lumped for comparisons with extant orangutans. Fossil orangutans show a general trend for thicker AET in postcanine teeth than extant orangutans (Figure 3), which is significantly greater in maxillary and mandibular M1s (Table 3). Fossil orangutans also
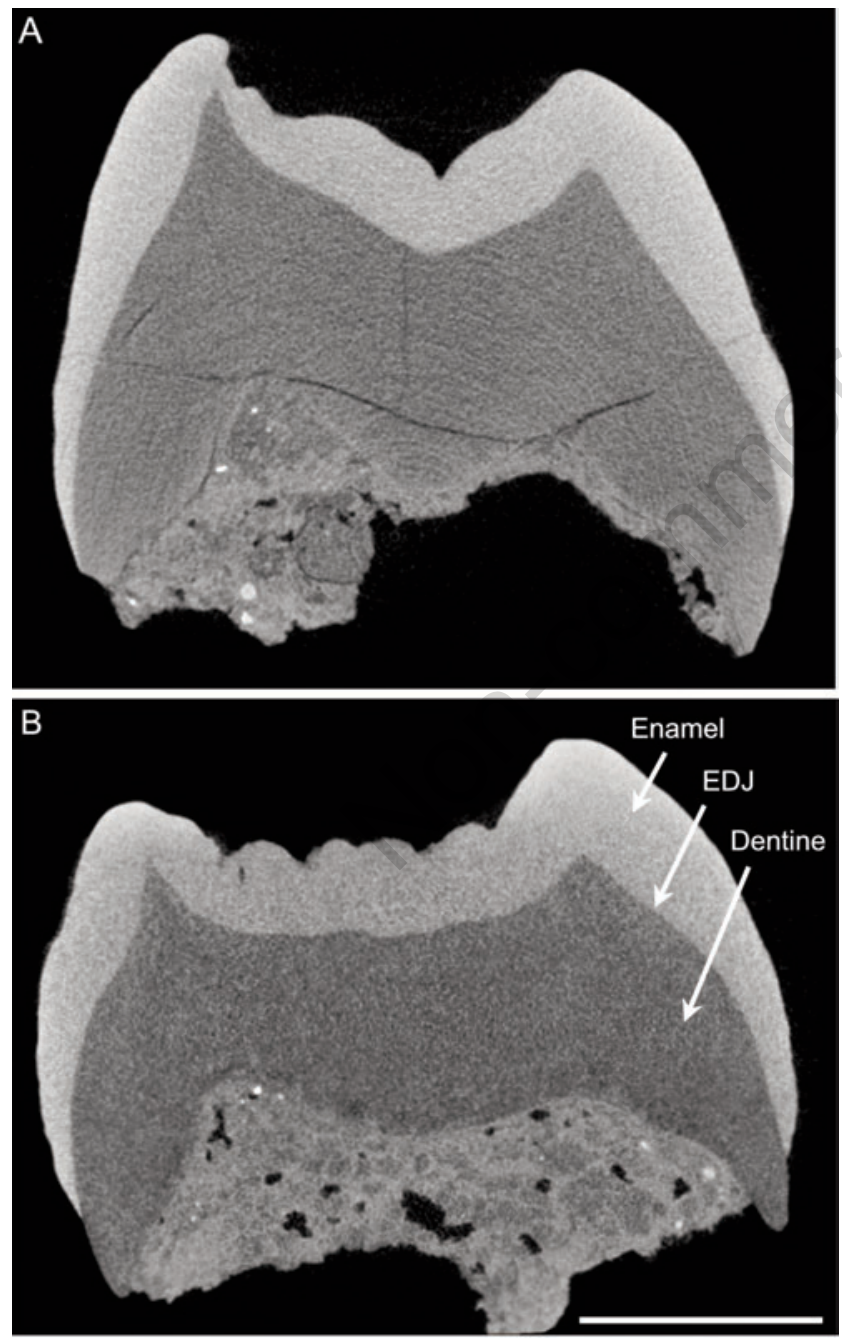

Figure 1. Virtual section of an unerupted Vietnamese fossil orangutan maxillary fourth premolar (A) and maxillary second molar (B). The area of the enamel cap, enamel-dentine junction (EDJ) length, and the area of dentine and pulp enclosed by the enamel cap were measured for enamel thickness quantification. Scale bar: $5 \mathrm{~mm}$.
Table 2. Mann-Whitney $U$ test of enamel thickness components and indices between fossil orangutan molars (by region).

\begin{tabular}{lcccccc} 
Tooth & Stat & $\mathrm{c}$ & $\mathrm{e}$ & $\mathrm{AET}$ & $\mathrm{b}$ & RET \\
\multirow{2}{*}{ UM1 } & $Z$ & -0.595 & -0.794 & -0.595 & -1.350 & -0.159 \\
& $p$ & 0.552 & 0.427 & 0.552 & 0.177 & 0.874 \\
UM2 & $Z$ & -0.179 & -0.090 & -0.090 & -0.537 & -0.537 \\
& $p$ & 0.858 & 0.929 & 0.929 & 0.591 & 0.591 \\
\hline UM3 & $Z$ & -1.334 & -1.698 & 0.000 & -1.940 & -1.091 \\
& $p$ & 0.182 & 0.090 & 1.000 & 0.052 & 0.275 \\
LM1 & $Z$ & -3.549 & -1.183 & -2.880 & -2.315 & -1.594 \\
& $p$ & $<0.001$ & 0.237 & 0.004 & 0.021 & 0.111 \\
\hline
\end{tabular}

c, Cross-sectional area of enamel; e, enamel-dentine junction length; AET, average enamel thickness; $b$, cross-sectional dentine area; RET, relative enamel thickness; UM, maxillary molar; LM, mandibular molar Second and third mandibular molar samples were too small to compare between regions. See Figure 2 for illustration of AET data.
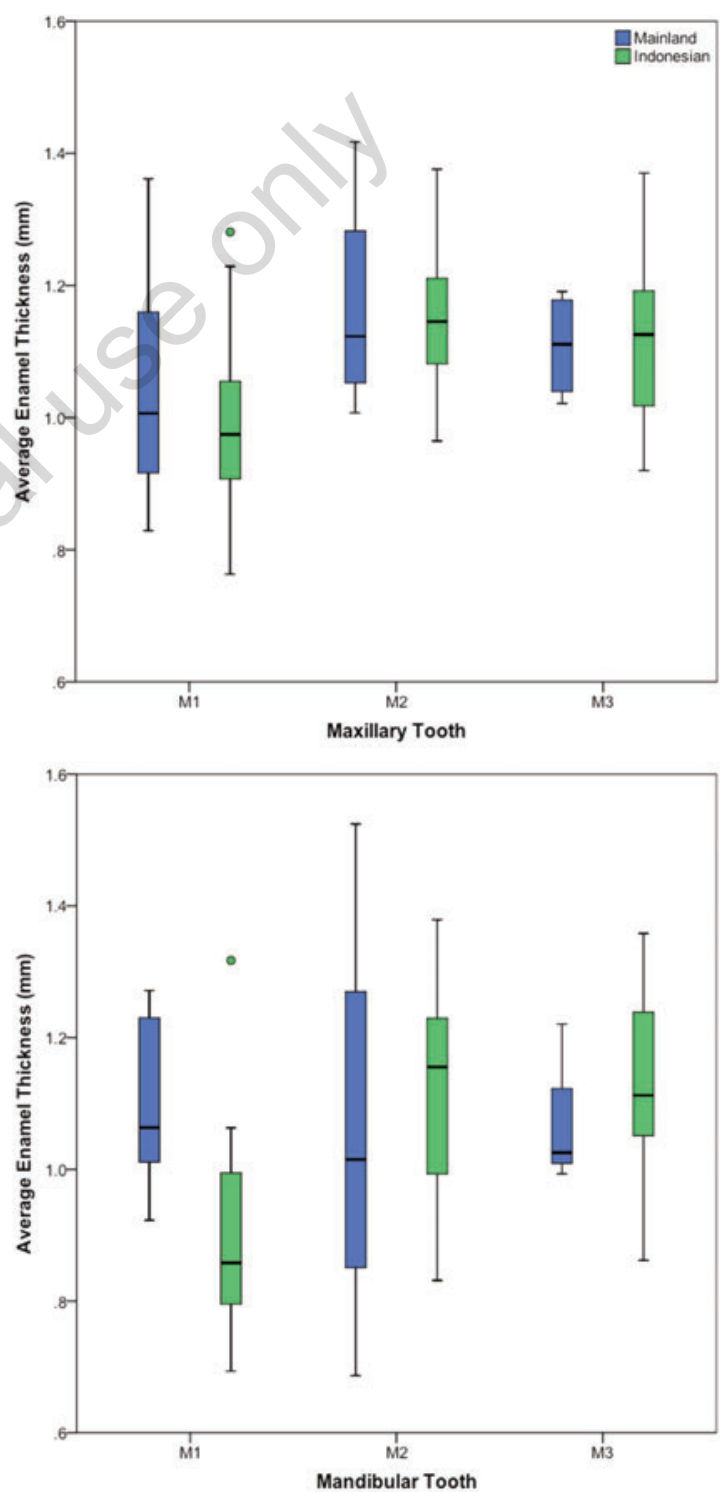

Figure 2. Comparison of average enamel thickness in fossil orang utan molars from mainland Asia and Indonesia. Standard box and whisker plots showing interquartile range $\left(25^{\text {th }}-75^{\text {th }}\right.$ percentiles: oxes), 1.5 interquartile ranges (whiskers) and the median values (black line). Outliers more than 1.5 interquartile ranges from the box are indicated with circles. 
Table 3. Mann-Whitney $U$ test of fossil and extant orangutan postcanine enamel thickness components and indices.

$\begin{array}{lccccccc}\text { Tooth } & \text { Stat } & \mathbf{c} & \mathrm{e} & \mathrm{AET} & \mathrm{b} & \mathrm{RET} & \mathrm{BCD} \\ \text { UM1 } & Z & -3.377 & -2.461 & -2.902 & -3.038 & -1.001 & -3.700 \\ & p & 0.001 & 0.014 & 0.004 & 0.002 & 0.317 & <0.001 \\ \text { UM2 } & Z & -2.966 & -2.884 & -1.124 & -2.478 & -1.016 & -3.751 \\ & p & 0.003 & 0.004 & 0.261 & 0.013 & 0.31 & <0.001 \\ \text { UM3 } & Z & -2.449 & -2.017 & -0.324 & -2.161 & -1.153 & -2.702 \\ & p & 0.014 & 0.044 & 0.746 & 0.031 & 0.249 & 0.007 \\ \text { LP3 } & Z & -1.132 & -0.793 & -0.453 & -0.679 & -0.34 & -1.812 \\ & p & 0.258 & 0.428 & 0.651 & 0.497 & 0.734 & 0.070 \\ \text { LP4 } & Z & -2.425 & -2.425 & -1.334 & -2.547 & -0.728 & -2.789 \\ & p & 0.015 & 0.015 & 0.182 & 0.011 & 0.467 & 0.005 \\ \text { LM1 } & Z & -3.625 & -2.259 & -3.153 & -2.512 & -1.602 & -2.917 \\ & p & <0.001 & 0.024 & 0.002 & 0.012 & 0.109 & 0.004 \\ \text { LM2 } & Z & -2.513 & -3.015 & -1.357 & -2.387 & -0.402 & -3.291 \\ & p & 0.012 & 0.003 & 0.175 & 0.017 & 0.688 & 0.001 \\ \text { LM3 } & Z & -2.970 & -2.673 & -1.287 & -2.838 & -1.155 & -3.664 \\ & p & 0.003 & 0.008 & 0.198 & 0.005 & 0.248 & <0.001\end{array}$

c Cross-sectional area of enamel; e enamel-dentine junction length; AET, average enamel thickness; cross-sectional dentine area; RET, relative enamel thickness; $\mathrm{BCD}$, bi-cervical diameter; UM, maxillary molar; LM, mandibular molar. Maxillary premolar samples were too small to compare. See Figures 3 and 4 for illustration of AET and RET data.
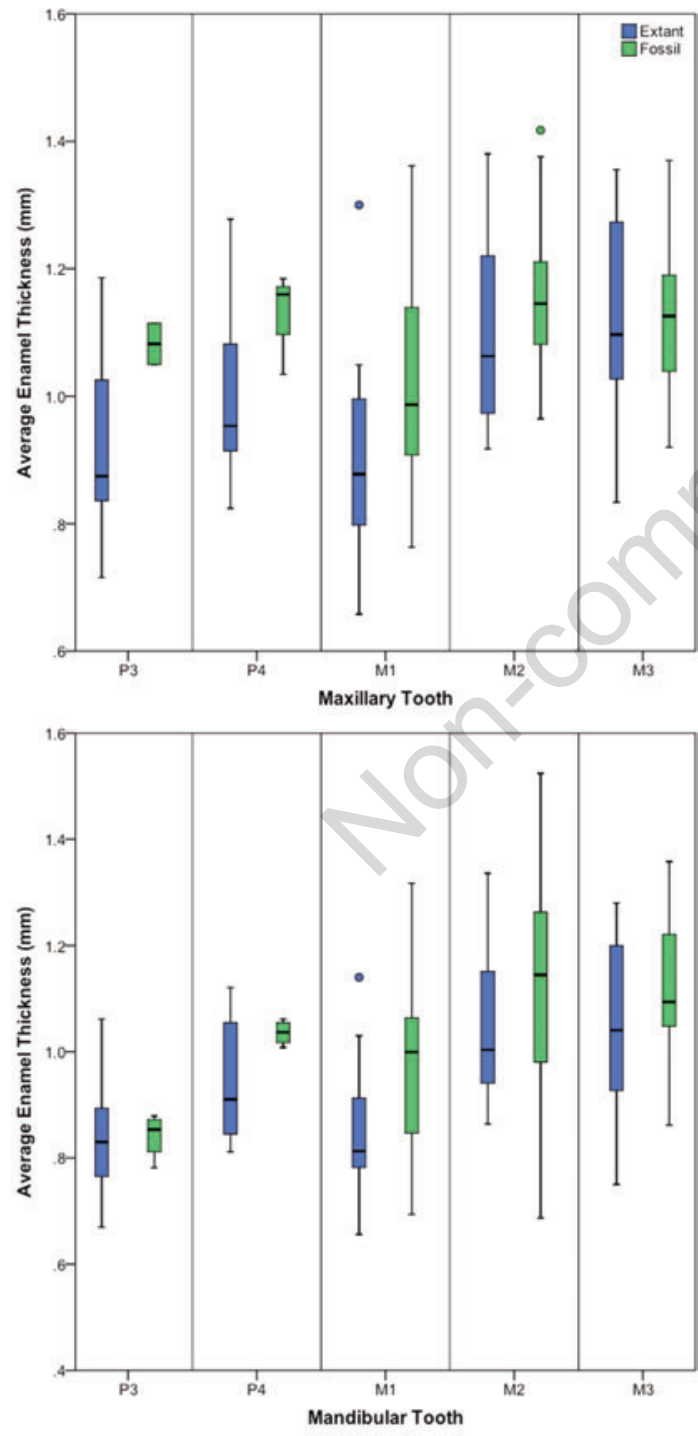

Figure 3. Comparison of average enamel thickness in extant and fossil orangutan postcanine teeth. See Figure 2 for explanation of data presentation. showed significantly higher enamel cap areas, enamel-dentine junction lengths, dentine areas, and bi-cervical diameter for most postcanine teeth (Table 3). No differences were found in RET between fossil and extant groups (Figure 4, Table 3).

\section{Discussion}

Comparisons of enamel thickness indices between mainland Asian and Indonesian orangutans reveal few differences, save for mandibular M1s, despite slight differences in tooth size. ${ }^{1,15}$ This study also reveals that fossil orangutan postcanine teeth show greater AET (but not RET) than extant orangutans. Comparisons of the components of enamel thickness indices (as well as bi-cervical diameter, a proxy for size) show significant differences across the majority of the postcanine dentition, which is examined further below. The finding of significant differences in M1 AET between fossil and extant orangutans parallels differences between regional groups of fossil taxa, and warrants further study. For example, assessment of incremental development may be used to determine if fossil and extant orangutans show differences in
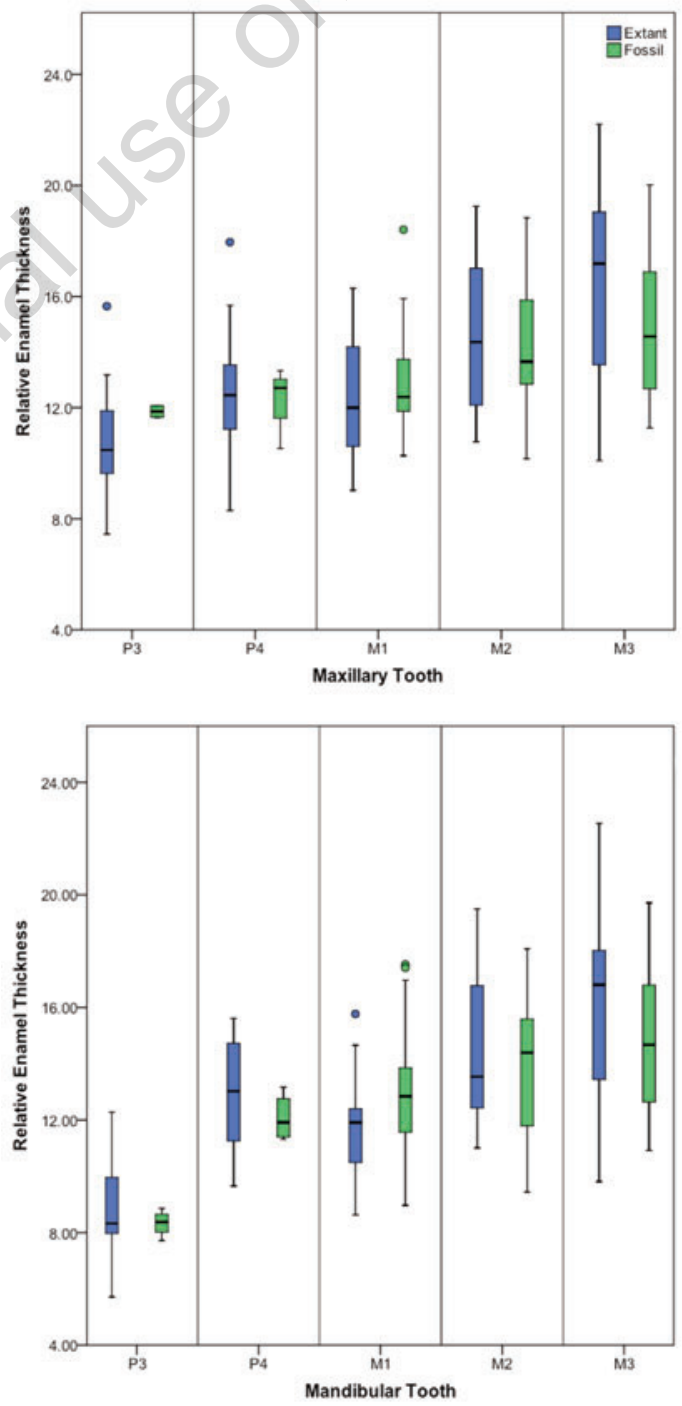

Figure 4. Comparison of relative enamel thickness in extant and fossil orangutan postcanine teeth. See Figure 2 legend for explanation of data presentation. 


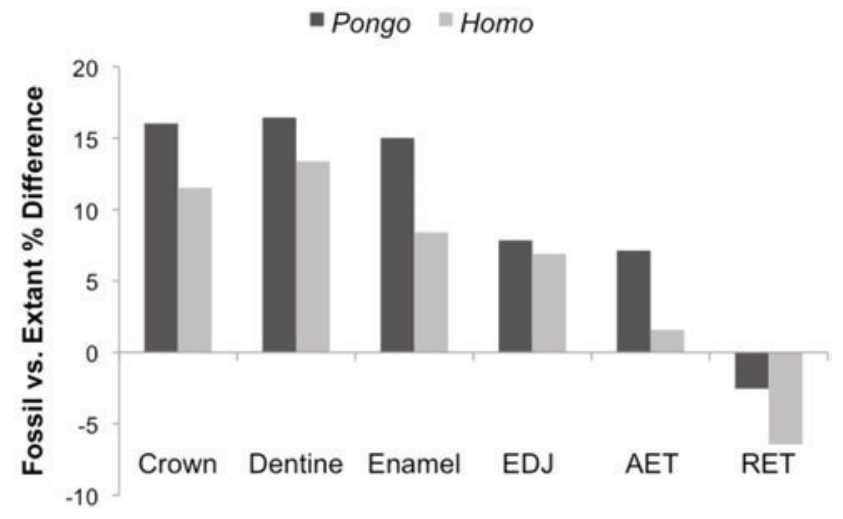

Figure 5. Dental tissue reduction in fossil and extant orangutans and humans. Percent differences were calculated as: 1 (extant/fossil) * 100. Crown: cross-sectional area of 2D mesial molar sections; dentine: cross-sectional dentine area (Martin's ${ }^{41,45}$ variable b); enamel: cross-sectional enamel area (Martin's 41,45 variable c); EDJ: enamel-dentine junction length (Martin's ${ }^{41,45}$ variable e); AET: average enamel thickness, calculated as enamel/EDJ (c/e); RET: relative enamel thickness, calculated as AET/square root dentine area $[(\mathrm{c} / \mathrm{e}) /$ sq. rt.b]. Pongo sample includes all available fossil and extant molar material (weighted to equalize representation of molar positions). Homo sample includes 271 recent and 17 fossil $H$. sapiens molars 35,38 (Supplementary Table 1) weighted to equalize representation of molar positions.

the timing or patterning of molar formation, as appears to be the case between species of Homo.46

The orangutan fossil record is similar to that of the genus Homo in certain respects. In addition to their relatively broad geographic ranges during the Pleistocene, both Pongo and Homo have both undergone dental reduction over time. Moreover, humans have preferentially reduced the size of their masticatory apparatus (reviewed in ${ }^{35}$ ), which has also been suggested for orangutans. ${ }^{8}$ Most extant human populations show smaller teeth that fossil Homo, including fossil Homo sapiens. ${ }^{13}$ Temporal changes in dental tissue proportions may be compared in both Pongo and Homo, assuming that available fossil samples are similar to the ancestors of respective extant populations. Orangutan molar crown areas in our sample have reduced by approximately $16 \%$, due to nearly equal reduction of enamel and dentine (Figure 5). In contrast, $H$. sapiens crown areas have reduced by $\sim 11.5 \%$, which is due to a greater decrease in dentine $(\sim 13 \%)$ than enamel $(\sim 8 \%)$. Grine found a similar pattern of preferential dentine reduction from first to third modern human molars, ${ }^{47}$ while Olejniczak et al. ${ }^{48}$ reported that Neanderthals and extant humans also show differences in dental tissue proportions. Modern humans appear to deviate from an isometric reduction of dental tissues, which may be due to selective pressure to preferentially retain enamel while reducing the size of tooth roots and jaws. Alternatively, human tooth crowns may be subject to developmental constraints that affect the rate of tissue reduction. Additional study is needed to resolve this.

These results have important implications for the calculation of conventional enamel thickness indices. Martin ${ }^{41,45}$ developed the relative enamel thickness index in order to compare enamel thickness across different-sized taxa. However, dentine area may not be a consistent predictor of body size, as fossil orangutan molars have significantly larger dentine cores, yet fossil and extant orangutans body masses appear to be broadly comparable. ${ }^{9}$ Moreover, given that enamel thickness indices are based on both area and linear measurements, geometric scaling influences these values differently, leading to greater changes in area than in linear dimensions (as in orangutans, thus cre- ating differences in AET). Finally, congeneric dental tissue changes do not necessarily scale isometrically, affecting enamel thickness indices in different ways. Although both orangutans and humans show dental reduction, humans show little change in AET but a more marked change in RET, and orangutans show the opposite pattern.

While orangutan dental evolution followed a slightly different pattern than in Homo, it is not clear whether the enamel thickness condition in extant Pongo primarily represent a dietary signal, or if it should also be understood in the context of phyletic dwarfing. ${ }^{16}$ Thick enamel is often interpreted an adaptation to resist tooth damage and/or abrasion while feeding on hard, brittle, or abrasive objects.33,34 The lower AET found in extant orangutans relative to fossil populations may indicate a change in dietary behavior towards less mechanically demanding or abrasive food, although orangutans have a broad and variable diet (reviewed in 29,30 ), as is true of recent human populations.

The oldest fossil orangutan remains are currently from Early or Middle Pleistocene deposits at Sangiran, Java, ${ }^{2,15}$ which have proven difficult to distinguish from Homo erectus teeth. ${ }^{36}$ Both taxa show relatively low crowned, crenulated molars that overlap in size, complicating identification of isolated molars. The finding of moderately thick enamel in the postcanine dentition of fossil orangutans in the current study may represent another convergent similarity with $H$. erectus. Some have suggested that the slightly more recent Javanese molars from Trinil represent fossil orangutans. ${ }^{15}$ However, a recent study of tooth development and structure has demonstrated that the Trinil molars are more similar to $H$. erectus than to living or fossil orangutans. ${ }^{37}$ Future studies that combine a suite of internal structural and developmental characters, including enamel-dentine junction shape and enamel distribution, may provide better taxonomic discrimination than traditional analyses of tooth size and shape.

\section{References}

1. D.A. Hooijer. Prehistoric teeth of man and of the orang utan from central Sumatra, with notes on the fossil orang utan from Java and Southern China. Zool. Meded. Leiden 29, 175-301 (1948).

2. G.H.R. von Koenigswald. Distribution and evolution of the orang utan, Pongo pygmaeus (Hoppius). In: L.E.M. de Boer (Ed.), The Orang utan. Its Biology and Conservation, pp. 1-15. The Hague, Dr. W. Junk Publishers (1982).

3. G.M. Drawhorn. The Systematics and Paleodemography of Fossil Orangutans (Genus Pongo). Ph.D. Thesis, University of California, Davis (1995).

4. C.K. Ho et al. Dental evolution of the orang-utan in China. Hum. Evol. 10, 249-264 (1995).

5. J.H. Schwartz et al. A review of the Pleistocene hominoid fauna of the socialist republic of Vietnam (excluding Hylobatidae). Anthrop. Pap. Am. Mus. Nat. Hist. 76, 1-24. (1995).

6. T. Harrison. Archaeological and ecological implications of the primate fauna from prehistoric sites in Borneo. Bull. Indo-Pacific Prehist. Assoc. 20, 133-146 (2000).

7. D.A. Hooijer. The orang-Utan in Niah Cave pre-history. Sarawak Mus. J. 15-16, 408-421 (1960).

8. A-M. Bacon, V.T. Long. The first discovery of a complete skeleton of a fossil orang-utan in a cave of the Hoa Binh Province, Vietnam. $J$. Hum. Evol. 41, 227-241 (2001).

9. A-M. Bacon, V.T. Long. Erratum. The first discovery of a complete skeleton of a fossil orang-utan in a cave of the Hoa Binh Province, Vietnam. J. Hum. Evol. 42, 505 (2002).

10. S. McBrearty, N.G. Jablonski. First fossil chimpanzee. Nature 437, 105-108 (2005).

11. D.W. Cameron. Morphometric evolutionary trends in the dental 
complex of Pongo. Primates 42, 253-266 (2001).

12. L. Zhao et al. Fossil orangutan-like hominoid teeth from Late Pleistocene human site of Mulanshan cave in Chongzuo of Guangxi and implications on taxonomy and evolution of orangutan. Chinese Sci. Bull. 54, 3924-3930 (2009).

13. C.L. Brace et al. What big teeth you had grandma! Human tooth size, past and present. In: M.A. Kelley, C. Spencer Larsen (Eds.), Advances in Dental Anthropology, pp. 33-57, New York, Wiley-Liss (1991).

14. P. Brown et al. A new small-bodied hominin from the Late Pleistocene of Flores, Indonesia. Nature 431, 1055-1061 (2004).

15. T. Harrison et al. Primate biogeography and ecology on the Sunda shelf islands: a paleontological and zooarchaeological perspective. In: S.M. Lehman, J.G. Fleagle, (Eds.), Primate Biogeography, pp. 331-372. New York, Springer (2006).

16. R.J. Smith, D.R. Pilbeam. Evolution of the orang-utan. Nature 284, 447-448 (1980).

17. X. Xu, U. Arnason. The mitochondrial DNA molecule of Sumatran orangutan and a molecular proposal for two (Bornean and Sumatran) species of orangutan. J. Mol. Evol. 43, 431-437 (1996).

18. K.S. Warren. Speciation and intrasubspecific variation of Bornean orangutans, Pongo pygmaeus pygmaeus. Mol. Biol. Evol. 18, 472480 (2001).

19. Y. Zhang et al. Genetic divergence of orangutan subspecies (Pongo pygmaeus). J. Mol. Evol. 52, 516-526 (2001).

20. N. Arora et al. Effects of Pleistocene glaciations and rivers on the population structure of Bornean orangutans (Pongo pygmaeus). Proc. Nat. Acad. Sci. USA 107, 21376-21381 (2010).

21. D.P. Locke et al. Comparative and demographic analysis of orangutan genomes. Nature 469, 529-533 (2011).

22. J. de Vos. The Pongo faunas from Java and Sumatra and their significance for biogeographical and paleo-ecological interpretations. Proc. B 86, 417-425 (1983).

23. J. de Vos. Reconsideration of Pleistocene cave faunas from south China and their relation to the faunas of Java. Cour. Forsch. Instit. Senckenberg 69, 259-266 (1984).

24. R.L. Ciochon. Divorcing hominins from the Stegodon-Ailuropoda fauna: new views on the antiquity of hominins in Asia. In J.G. Fleagle, J.J. Shea, F.E. Grine, A.L. Baden, R.E. Leakey (Eds.), Out of Africa I: The First Hominin Colonization of Eurasia, pp. 111-126. Vertebrate Paleobiology and Paleoanthropology, Dordrecht, Springer (2010).

25. J. Courtenay et al. Inter- or intra-island variation? An assessment of the differences between Bornean and Sumatran orang-utans. In: J.H. Schwartz (Ed.), Orang-utan Biology, pp. 19-29. New York, Oxford University Press (1988).

26. C.P. Groves et al. Unfinished business: Mahalanobis and a clockwork orang. J. Hum. Evol. 22, 327-340 (1992).

27. A. Uchida. Variation in tooth morphology of Pongo pygmaeus. $J$. Hum. Evol. 34, 71-79 (1998).

28. T.M. Smith et al. Variation in hominoid molar enamel thickness. $J$. Hum. Evol. 48, 575-592 (2005).
29. T.M. Smith et al. Enamel thickness in Bornean and Sumatran orangutan dentitions. Am. J. Phys. Anthrop. (in review)

30. A.B. Taylor. Feeding behavior, diet, and the functional consequences of jaw form in orangutans, with implications for the evolution of Pongo. J. Hum. Evol. 50, 377-393 (2006).

31. E.R. Vogel et al. Linking feeding ecology and jaw form in two species of wild orangutans. Am. J. Phys. Anthrop. Suppl. 52, 301 (2011).

32. D.G. Gantt. The enamel of Neogene hominoids. In: R.L. Ciochon, R.S. Corruccini (Eds.), New Interpretations of Ape and Human Ancestry, pp. 249-298. New York, Plenum Press (1983).

33. M.F. Teaford, P.S. Ungar. Diet and the evolution of the earliest human ancestors. Proc. Nat. Acad. Sci. USA 97, 13506-13511 (2000).

34. P.W. Lucas et al. Inferences regarding the diet of extinct hominins: structural and functional trends in dental and mandibular morphology within the hominin clade. J. Anat. 212, 486-500 (2008).

35. T.M. Smith et al. Variation in enamel thickness within the genus Homo. J. Hum. Evol. (in press)

36. F. Grine, J.L. Franzen. Fossil hominid teeth from the Sangiran Dome (Java, Indonesia). Cour. Forsch. Instit. Senckenberg 171, 75103 (1994).

37. T.M. Smith et al. Taxonomic assessment of the Trinil molars using non-destructive 3D structural and developmental analysis. PaleoAnthrop. 2009, 117-129 (2009).

38. T.M. Smith et al. Modern human molar enamel thickness and enamel-dentine junction shape. Arch. Oral Biol. 51, 947-995 (2006).

39. T.M. Smith et al. Molar crown thickness, volume, and development in South African Middle Stone Age humans. S. Afr. J. Sci. 102, 513517 (2006).

40. T.M. Smith et al. Enamel thickness trends in the dental arcade of humans and chimpanzees. Am. J. Phys. Anthrop. 136, 237-241 (2008).

41. LB. Martin. The relationships of the Later Miocene Hominoidea. Ph.D. Thesis. University College London, London (1983).

42. R.F. Kay. The nut-crackers - a new theory of the adaptations of the Ramapithecinae. Am. J. Phys. Anthrop. 55, 141-151 (1981).

43. P. Andrews, L. Martin. Hominoid dietary evolution. Phil. Trans. Roy. Soc. Lond. B Biol. Sci. 334, 199-209 (1991).

44. R.N.M. Feeney et al. Enamel thickness in Asian human canines and premolars. Anthrop. Sci. 118, 191-198 (2010).

45. L. Martin. Significance of enamel thickness in hominoid evolution. Nature 314, 260-263 (1985).

46. T.M. Smith et al. Dental evidence for ontogenetic differences between modern humans and Neanderthals. Proc. Nat. Acad. Sci. USA 107, 20923-20928 (2010).

47. F.E. Grine. Enamel thickness of deciduous and permanent molars in modern Homo sapiens. Am. J. Phys. Anthrop. 126, 14-31 (2005).

48. A.J. Olejniczak et al. Dental tissue proportions and enamel thickness in Neandertal and modern human molars. J. Hum. Evol. 55, 12-23 (2010). 